Scientific Paper

\title{
Comparison of three and four- field radiotherapy technique and the effect of laryngeal shield on vocal and spinal cord radiation dose in radiotherapy of non-laryngeal head and neck tumors
}

\author{
Noushin HASSAN POUR ${ }^{1,2}$, Alireza FARAJOLLAHI ${ }^{3,2,4, a}$, Masoud JAMALI ${ }^{5}$, Ahad ZEINALI ${ }^{6}$, Amir Ghasemi JANGJOU ${ }^{4}$ \\ ${ }^{I}$ Immunology Research Center, Tabriz University of Medical Sciences, Tabriz, Iran \\ ${ }^{2}$ Department of Medical Physic, Faculty of Medicine, Tabriz University of Medical Science, Tabriz, Iran \\ ${ }^{3}$ Medical Education Research Center, Tabriz, Iran \\ ${ }^{4}$ Imam Reza University Hospital, Radiotherapy Department, Tabriz University of Medical Science, Tabriz, Iran \\ ${ }^{5}$ Radiotherapy Center of Omid Hospital, Urmia, Iran \\ ${ }^{6}$ Department of Medical Physic, Urmia University of Medical Science, Urmia, Iran \\ ${ }^{a}$ E-mail address: farajollahiar@gmail.com
}

(received 12 September 2017; revised 9 and 29 January 2018; accepted 6 February 2018)

\begin{abstract}
Introduction: Due to the effect of radiation on both the tumor and the surrounding normal tissues, the side effects of radiation in normal tissues are expected. One of the important complications in the head and neck radiotherapy is the doses reached to the larynx and spinal cord of patients with non-laryngeal head and neck tumors.

Materials and Methods: In this study, CT scan images of 25 patients with non-laryngeal tumors including; lymph nodes, tongue, oropharynx and nasopharynx were used. A three-field and a four-field treatment planning with and without laryngeal shield in 3D CRT technique were planned for each patient. Subsequently, the values of Dmin, Dmean, Dmax and Dose Volume Histogram from the treatment planning system and NTCP values of spinal cord and larynx were calculated with BIOPLAN and MATLAB software for all patients.

Results: Statistical results showed that mean values of doses of larynx in both three and four-field methods were significantly different between with and without shield groups. Comparison of absorbed dose didn't show any difference between the three and four field methods ( $P>0.05)$. Using Shield, just the mean and minimum doses of spinal cord decreased in both three and four fields. The NTCP of the spinal cord and larynx by three and four-field methods with shield in the LKB and EUD models significantly are less than that of the three and four fields without shields, and in the four-field method NTCP of larynx is less than three radiation field.

Conclusion: The results of this study indicate that there is no significant difference in doses reached to larynx and spinal cord between the treatments techniques, but laryngeal shield reduce dose and NTCP values in larynx considerably.
\end{abstract}

Key words: 3D CRT; larynx; spinal cord; DVH; NTCP

\section{Introduction}

The global incidence of head and neck cancers is about 650,000 cases per year, which accounts for $6 \%$ of all cancers. Head and neck cancers include a heterogeneous group of gastrointestinal and upper respiratory tract tumors, paranasal sinuses, salivary glands, and thyroid gland [1,2].

Radiation therapy, along with chemotherapy and surgery, plays an important role in the treatment of head and neck tumors. The most common purpose of radiotherapy is to deliver a therapeutic dose to the tumor without damaging the surrounding tissues $[3,4]$. The radiotherapy process begins by performing a patient's scan. The radiation oncologist then specifies the treatment volume for purpose of treatment planning. Finally, the patient plan that has been produced by the physicist using treatment planning system (TPS) is transferred to the treatment machine. The importance of all these processes are to ensure accurate treatment of the patient by a proper treatment plan [4]. Over the past two decades, in order to reduce the complications of radiotherapy and increase the therapeutic efficacy, treatment planning techniques have been significantly improved. Today radiotherapy can be done with techniques of 3D CRT, IMRT, VMAT, etc. 3D conformal technique (3D CRT), unlike the conventional treatments uses a computer to determine the precise extent of the tumor. In this technique, the healthy tissue around the tumor receives less doses than tumor tissue due to precise contouring [1]. In the intensity modulated radiation therapy (IMRT) technique, which is a new type of 3D CRT radiotherapy, usually different intensity of x-rays are used to transmit different doses of 
radiation to small tissue areas simultaneously. In this technique, high doses reach more exactly to the tumor and lower dose to surrounding healthy tissues $[5,6]$. The most modern and complex of these modes is volumetric modulated arc therapy (VMAT), which rotates the gantry of the linear accelerator around the patient for a partial or full arc at a constant or variable rate [7]. However 3D CRT is still applied for the treatment of head and neck cancers in most radiotherapy centers regardless of its shortcoming in comparison to the highly modulated techniques [8].

Radiation therapy of head and neck tumors has a particular complexity due to the location and complications of normal tissues. Anatomy of the patient, the presence of several targets with different prescribed doses, the extent of the treatment area and the presence of a large number of sensitive tissues such as spinal cord, salivary glands, thyroid and larynx are the reason of the difficulty of treating head and neck tumors [2].

The important complication of radiotherapy in the head and neck, which minimize it from the duties of radiotherapy and medical physicians, are spinal cord and vocal cords injury that have a significant impact on the patients' daily activities and their life expectancy $[9,10]$.

Radiation damage to the spinal cord can cause paralysis, numbness, and impairment in the function and control of the bladder and intestine [11,12]. According to the articles, in order to reduce secondary complications, the highest tolerable spinal cord dose is 45-50 Gy [4,13]. Loss of speech and voice quality and laryngeal edema is due to unnecessary laryngeal radiation during treatment of head and neck tumors [14]. Therefore, low voice quality was reported between 24-72 months after radiotherapy in patients with non-laryngeal tumors of head and neck with mean laryngeal dose of $56 \mathrm{~Gy}$ [15]. It is also recommended to reduce laryngeal edema, the percentage of larynx volume that receives more than $50 \mathrm{~Gy}$ is less than $27 \%$ and the average larynx dose is kept about 44 Gy [16].

Since routine treatment of head and neck tumors involves the use of split three-fields technique, including two lateral fields for primary tumor and neck lymph nodes and anterior field for the supraclavicular lymph nodes [17,18]. But experience has shown that in some patients with a relatively large chest volume with supraclavicular lymph nodes in depth, it seems that the four-field technique with combined photon beams consist of two lateral fields with $6 \mathrm{MV}$ and two opposite supraclavicular fields, anterior and posterior, with 6 and 15 MV beams, respectively would be better. Therefore, in this study, the doses reached to the spinal cord and larynx in nonlaryngeal tumors with three and four fields of 3D CRT technique as well as the effectiveness of laryngeal shield in the above techniques was evaluated. Additionally, the complications of normal tissue of larynx and spinal cord were studied using two models of Lyman-Kutcher-Burman (LKB) and equivalent uniform dose (EUD).

\section{Materials and methods}

In this study, CT scan's data of 25 patients with non-laryngeal head and neck tumors was used, including oropharynx, tongue, nasopharynx and lymph nodes tumors referring to the Department of Radiotherapy of Omid Hospital in Urmia. Table 1 shows the demographic and clinical data of patients.

Table 1. Patient characteristics

\begin{tabular}{lc}
\hline \hline Characteristics & Number of patients (\%) \\
\hline Gender & $16(64 \%)$ \\
1 - male & $9(36 \%)$ \\
2 - female & \\
\hline Site of primary tumor & $10(40 \%)$ \\
1 - Oropharynx & $7(28 \%)$ \\
2 - Oral cavity & $5(20 \%)$ \\
3 - Nasopharynx & $3(12 \%)$ \\
4 - Lymph nodes & \\
\hline $\mathrm{TNM}$ stages & $10(40 \%)$ \\
1 - $\mathrm{T}_{2} \mathrm{~N}_{0} \mathrm{M}_{0}$ & $13(52 \%)$ \\
$2-\mathrm{T}_{3} \mathrm{~N}_{0} \mathrm{M}_{0}$ & $2(8 \%)$ \\
$3-\mathrm{T}_{4} \mathrm{~N}_{0} \mathrm{M}_{0}$ & \\
\hline \hline
\end{tabular}

For planning of 3D CRT, the Core Plan treatment planning System was used. In this study, after loading CT scans of patients from the software archive into the functional environment, the volume of the tumor (GTV) and the volume of sensitive tissue (OARs) of larynx and spinal cord was prescribed by oncologist and for each patient the total dose of $4400 \mathrm{cGy}$ in 22 sessions was administered for the first stage of treatment.

Subsequently, for all CT scan data, the present study includes the three-field method (two lateral opposed and one anterior supraclavicular field) with and without the application of lead shield in the anterior field with $6 \mathrm{MV}$ photon beam and fourfield technique (two lateral cervical fields and two anterior and posterior supraclavicular fields) with and without laryngeal shields with $6 \mathrm{MV}$ photon beam, and posterior field of supraclavicular with the $15 \mathrm{MV}$ beam were designed. The size of the lead shield was varied in each patient based on anatomy of the laryngeal tissue on that patients. The effect of shield on the dose distribution in both three and four-field are shown in Figures 1 and 2.

In order to distribute the optimal dosage in the irradiated area and prevent the increase in the dose of sensitive organs, especially larynx, in the four-field method, the weighting technique was applied to supraclavicular opposed beams. In this case the dose contribution of AP and PA beams was 1.3 $(65 \%)$ and $0.7(35 \%)$ respectively. 


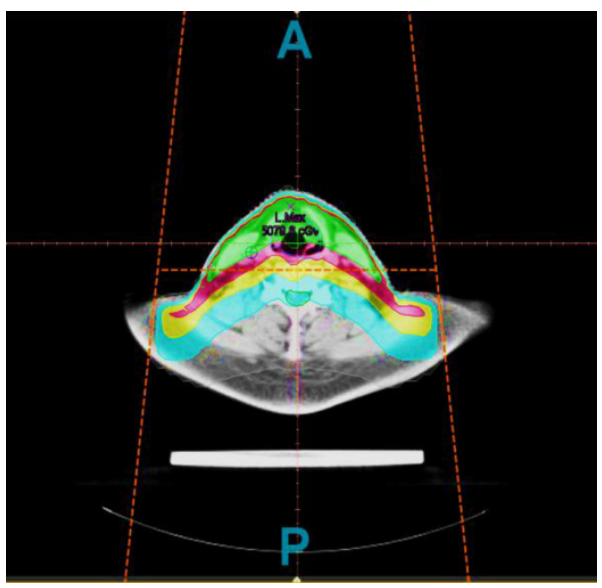

(a)

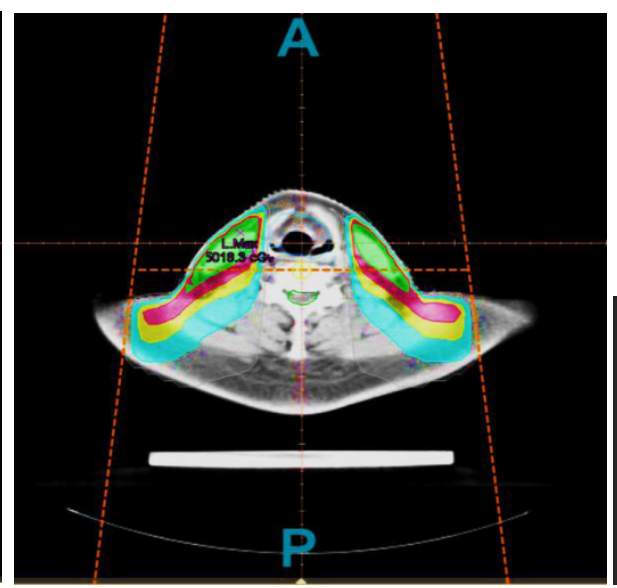

(b)

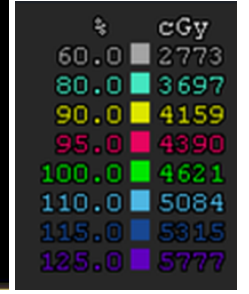

Figure 1. Dose distribution curve in AP Supraclavicular Field in three-field method. $(a)=$ without shield, $($ b) $=$ with shield.

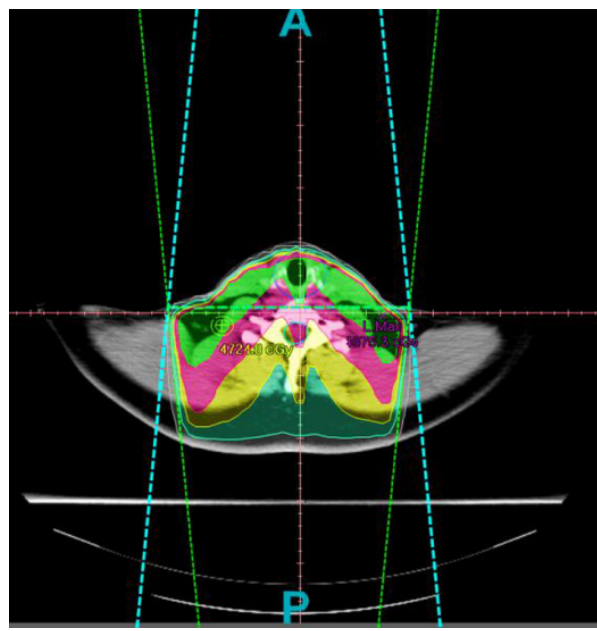

(a)

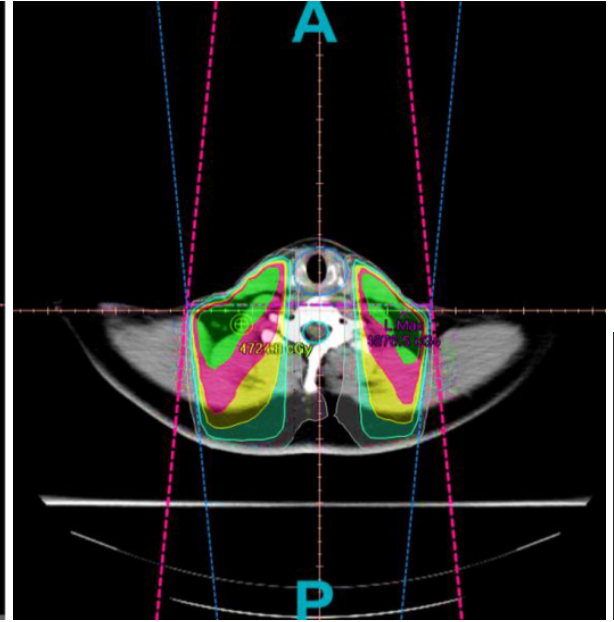

(b)

Figure 2. Dose distribution curve in AP and PA Supraclavicular Field in four-field method. (a) = without shield, (b) = with shield.

After treatment planning, Dose volume histograms (DVH), minimum Dose, mean Dose and maximum Dose values of spinal cord and larynx were extracted and evaluated for all patients. Also radiobiological coefficients related to normal tissues of larynx and spinal cord in head and neck tumors were extracted from the previous articles and studies depending on the model. Then the normal tissue complication probability (NTCP) was calculated and compared through the BIOPLAN and MATLAB software with LKB and EUD models, respectively. The data were analyzed by means of paired t-test and two factors ANOVA using SPSS.18 software.

\section{Software used to calculate the normal tissue complications probability}

BIOPLAN software (1.3.3): This software was written by Nahum and Sanchez-Nieto in 2000 [19]. This software calculates the probability of tumor control based on the Poisson model and the probability of normal tissue complications based on the LKB and Relative Seriality models. The LKB model is obtained from the following equation:

$$
\begin{aligned}
& N T C P=\frac{1}{\sqrt{2 \pi}} \int_{-\propto}^{t} e^{\left(\frac{-t^{2}}{2}\right)} d t \\
& t=\frac{D_{e f f-T D_{50}}}{\mathrm{~m} T D_{50}} \\
& D_{\text {eff }}=\left(\sum_{i} v_{i} D_{i}^{\frac{1}{n}}\right)^{n}
\end{aligned}
$$

In the $\mathrm{LKB}$ model, the three parameters $\mathrm{TD}_{50}, \mathrm{~m}, \mathrm{n}$ are defined for the calculation of NTCP; $\mathrm{TD}_{50}$ is a dose that has a $50 \%$ risk of complication, $\mathrm{m}$ is the slope of the sigmoid curve and $\mathrm{n}$ is the parameter of the tissue volume effect. Deff is a dose that is uniformly equivalent to the EUD and $v_{i}$ is the fraction of the organ volume that receives $D_{i}$ dose. Table 2 lists the $n, m$, $\mathrm{TD}_{50}$ and $\alpha / \beta$ parameters for the larynx and spinal cord with end points considered by Emami et al and Rancati et al. To use the BIOPLAN software, DVH data must be changed to dDVH format that it can be done using the MATLAB software. 


\section{Software related to EUD model}

The EUD model was written in 2007 on the basis of the MATLAB. With the EUD model, the tumor control probability and the normal tissue complications probability and EUD (Gy) can be calculated. For EUD model, the DVH obtained from the treatment planning system is presented in the form of a dosevolume chart for which another program is written in MATLAB. The EUD model is obtained using the following equation [26-29]:

$$
\begin{array}{ll}
E U D=\left[\sum_{i=1}^{N} \mathrm{v}_{i} \cdot\left(D^{a}\right)\right]^{1 / a}, \text { where } \mathrm{a}=1 / \mathrm{n} & \text { Eq. } 4 \\
N T C P=\frac{1}{1+\left(\frac{T D_{50}}{E U D}\right)^{4} \gamma_{50}} & \text { Eq. } 5
\end{array}
$$

The parameters of the EUD model for NTCP include: TD $_{50}$ is the tolerance dose for a $50 \%$ complication, a is parameter without unit for the normal tissue or tumor and $\gamma_{50}$ is parameter describing the slope of the response-dose curve [25]. Table 3 lists the parameters for the spinal cord and larynx taken into account their end points in the EUD model. With the parameter $\mathrm{a}=1 / \mathrm{n}$ gives the same NTCP as the LKB dose volume histogram reduction procedure [26].

Table 2. Parameters of the LKB model for calculating NTCP in the laryngeal and spinal cord tissues [22-24].

\begin{tabular}{cccccc}
\hline \hline Organ & $\mathbf{n}$ & $\mathbf{m}$ & TD $_{\mathbf{5 0}}(\mathbf{G y})$ & $\boldsymbol{\alpha} / \boldsymbol{\beta}(\mathbf{G y})$ & End point \\
\hline $\begin{array}{c}\text { Spinal cord } \\
\text { Emami et al }\end{array}$ & 0.05 & 0.175 & 66.5 & 2 & $\begin{array}{c}\text { Myelitis/ } \\
\text { necrosis }\end{array}$ \\
\hline $\begin{array}{c}\text { Larynx } \\
\text { Emami et al }\end{array}$ & 0.08 & 0.17 & 70 & 3.8 & $\begin{array}{c}\text { Laryngeal } \\
\text { edema }\end{array}$ \\
\hline $\begin{array}{c}\text { Larynx } \\
\text { Rancati et al }\end{array}$ & 0.045 & 0.16 & 46.3 & 3.8 & $\begin{array}{c}\text { Laryngeal } \\
\text { edema }\end{array}$ \\
\hline \hline
\end{tabular}

Table 3. Parameters of the EUD model for calculating NTCP in the larynx and spinal cord tissues

\begin{tabular}{cccccc}
\hline \hline Organ & a & $\boldsymbol{\gamma}_{\mathbf{5 0}}$ & $\mathbf{T D}_{\mathbf{5 0}}(\mathbf{G y})$ & $\boldsymbol{\alpha} / \boldsymbol{\beta}(\mathbf{G y})$ & End point \\
\hline $\begin{array}{c}\text { Spinal cord } \\
\text { Emami et al }\end{array}$ & 7.4 & 4 & 66.5 & 2 & $\begin{array}{c}\text { Myelitis/ } \\
\text { necrosis }\end{array}$ \\
\hline $\begin{array}{c}\text { Larynx } \\
\text { Emami et al }\end{array}$ & 12.5 & 4 & 70 & 3.8 & $\begin{array}{c}\text { Laryngeal } \\
\text { edema }\end{array}$ \\
\hline $\begin{array}{c}\text { Larynx } \\
\text { Rancati et al }\end{array}$ & 2.2 & 4 & 46.3 & 3.8 & $\begin{array}{c}\text { Laryngeal } \\
\text { edema }\end{array}$ \\
\hline \hline
\end{tabular}

\section{Results}

In this study, the effects of three and four radiation fields in the 3D CRT treatment on Dmin, Dmean, Dmax and NTCP values of sensitive organs of the spinal cord and larynx on the 25 patients with non-laryngeal head and neck tumors were investigated, and the results are presented in the Tables 4 and $\mathbf{5}$, respectively.

The statistical results showed that there is a significant difference between the mean of Dmin and Dmean of spinal cord in the three and four radiation fields between groups with and without shields with p-value $<0.01$, Clearly according to Table 4, despite that the minimum and mean doses of the spinal cord in the three-field technique with Shield were from $2061.61 \pm 1176.57$ to $863.56 \pm 292.91 \mathrm{cGy}$, and from 4055.26 \pm 178.74 to $3597.26 \pm 256.41 \mathrm{cGy}$, respectively, and in the group of four - fields, the Dmin decreased from $2071.54 \pm$ 1381.82 to $853.98 \pm 341.43 \mathrm{cGy}$ and the Dmean is from $4239.76 \pm 171.63$ to $3709.35 \pm 305.99 \mathrm{cGy}$, however, the maximum spinal cord doses were not different in both methods with and without shields.

Comparison of spinal cord doses in both three and four-field methods with and without shields shows that there is no significant difference between maximum and minimum spinal cord doses, but the Dmean of spinal cord in the four-field method in both cases with and without Shield was more than of three-field method( $p>0.05)$.

According to Table 4, the mean value of NTCP spinal cord in LKB and EUD models for both three and four fields using Shield was lower, but NTCP values in the four-field with and without shield methods compared to the same three-field method significantly increased with $p<0.05$.In the amount of EUD (Gy) (equivalent uniform doses) for the spinal cord in the three and four-field with and without shield, the significance of field and the shield's effect was less than 0.05 .

Table 5 shows the results of the larynx. To calculate normal tissue complication probability of larynx, two models of LKB and EUD were used with parameters of two papers by Emami et al. and Rancati et al. It should be noted that the present study only refers to the first stage of treatment tumors of the head and neck with a total dose of $4400 \mathrm{cGy}$ with emphasis on sensitive organs. The larynx and spinal cord, are located in the therapeutic field. Because of this, data related to the Emami's article with a dose of $7000 \mathrm{cGy}$ (approximate dosage of steps 1 , 2 and 3, for treatment of head and neck tumors). In addition to using the data from this paper, the parameters of calculating NTCP of the Rancati's article, which was limited less than 50Gy to prevent laryngeal edema during treatment, was used.

The mean laryngeal doses in the three-field method with and without shields were $2745.12 \pm 937.22$ and $4569.60 \pm 524.63$ cGy, respectively, and in the four-field with and without shields were $2745.9 \pm 915.85$ and $4643.98 \pm 73.54 \mathrm{cGy}$, respectively, as shown in table 5 , the maximum and minimum laryngeal dose also decreased significantly in the use of laryngeal shields $(\mathrm{p}<0.05)$, It should be noted that due to the similarity of the results of Dmin, Dmean, Dmax between two treatment planning, the four-field method does not show any superiority to the three-field method in both cases with and without shields for the larynx dose.

The value of normal tissue complication probability for laryngeal tissue with LKB model with Rancati's parameters, in the three-field without and with shield method was equal to $65.42 \pm 8.89$ and $6.40 \pm 8.53$ and in the four-field method, $55.81 \pm 6.64$ and $6 \pm 7.92$, respectively, which has a statistically significant difference between the two groups of without and with shield $(\mathrm{p}<0.01)$. As is seen, the NTCP level of larynx between the two techniques has different values and it is higher in the technique of three radiation fields. 
Table 4. Absorbed dose and normal tissue complication probability of spinal cord (mean \pm SD)

\begin{tabular}{cccc}
\hline \hline Parameter & Three-field & Three-field with shield & Four-field \\
\hline Dmin & $2061.61 \pm 1176.57$ & $863.56 \pm 292.91$ & $2071.54 \pm 1381.82$ \\
Dmean & $4055.26 \pm 178.74$ & $3597.26 \pm 256.41$ & $4239.76 \pm 171.63$ \\
Dmax & $4594.12 \pm 66.80$ & $4590.37 \pm 84.35$ & $4613.86 \pm 65.08$ \\
NTCP\%(LKB) & $2.63 \pm 0.43$ & $2.36 \pm 0.51$ & $3.12 \pm 0.57$ \\
NTCP\%(EUD) & $0.09 \pm 0.03$ & $0.07 \pm 0.03$ & $0.14 \pm 0.04$ \\
EUD(Gy) & $43.17 \pm 0.89$ & $42.38 \pm 1.18$ & $44.24 \pm 1.22$ \\
\hline \hline
\end{tabular}

Table 5. Absorbed dose and normal tissue complication probability of larynx (mean \pm SD)

\begin{tabular}{|c|c|c|c|c|}
\hline Parameter & Three-field & Three-field with shield & Four-field & Four-field with shield \\
\hline Dmin & $4049.56 \pm 932.41$ & $959.39 \pm 323.95$ & $4342.66 \pm 317.51$ & $963.78 \pm 344.31$ \\
\hline Dmean & $4569.60 \pm 524.63$ & $2745.12 \pm 937.22$ & $4643.98 \pm 73.54$ & $2745.91 \pm 915.85$ \\
\hline Dmax & $4945.03 \pm 213.32$ & $4430.54 \pm 650.07$ & $4845.75 \pm 105.11$ & $4404.48 \pm 658.42$ \\
\hline \multicolumn{5}{|l|}{ NTCP\%(LKB) } \\
\hline Emami et al & $4.52 \pm 1.38$ & $0.87 \pm 0.89$ & $3.04 \pm 0.72$ & $0.81 \pm 0.84$ \\
\hline \multicolumn{4}{|l|}{ NTCP\%(EUD) } & $6 \pm 7.92$ \\
\hline Emami et al & $0.45 \pm 0.25$ & $0.04 \pm 0.05$ & $0.23 \pm 0.09$ & $0.03 \pm 0.04$ \\
\hline $\begin{array}{c}\text { Rancati et al } \\
\operatorname{EUD}(\mathrm{Gy})\end{array}$ & $71.74 \pm 11.42$ & $2.45 \pm 4.06$ & $58.72 \pm 9.85$ & $2.23 \pm 3.88$ \\
\hline Emami et al & $49.85 \pm 1.72$ & $37.12 \pm 9.06$ & $47.51 \pm 1.26$ & $36.44 \pm 9.52$ \\
\hline Rancati et al & $49.27 \pm 1.82$ & $27.16 \pm 11.17$ & $47.38 \pm 1.31$ & $26.76 \pm 11.35$ \\
\hline
\end{tabular}

From the table, not only there is a significant difference in NTCP level between the LKB model with the Emami and Rancati's parameters, but also there is a statistically significant difference between the two groups with and without shields and between the radiation fields. The results of the EUD model with both Emami and Rancati methods for larynx show a significant difference $(p<0.05)$ between the groups with and without shields and the three and four fields groups in the larynx, despite the difference in the calculated value. The amount of NTCP in the larynx without shield is greater than with shield and in three fields more than the four field.

\section{Discussion}

To judge and compare between the two treatments, are needed many decisions by a radiotherapist. The physician should consider the delivered dose to the target volume, along with the side effects of radiation to the surrounding healthy tissues. The final decision on treatment planning is usually dependent on the tumor position, the extent of the disease, the physician's preference the estimates of treatment and its complications. The ultimate goal of any treatment is recovery and high quality of life [30]. Radiotherapy treatment plans are generally assessed by evaluating the 3D dose distributions calculated by a treatment planning system by analyzing the dose distribution superimposed on images of the patient anatomy and by examining DVHs, which are $2 \mathrm{D}$ representation of $3 \mathrm{D}$ dose information, for each organ or tumor volume of interest [31]. The results of this study indicate that the use of shield in the 3D-CRT method reduced the amount of Dmin and Dmean spinal cord to approximately $58 \%$ and $12 \%$ respectively in both treatment planning. But didn't effect on the Dmax. The Dmin, Dmean and Dmax value of the larynx in the with Shield method were $77 \%, 40 \%$, and $10 \%$,respectively less than the without shield in both radiation field, However, there is no significant difference between the therapeutic techniques of three and four fields in the doses reaching the spinal cord and larynx, which can be said that the studied therapeutic fields are not superior to each other; but NTCP values of the larynx and spinal cord showed remarkable results, so that the NTCP level of the larynx in the four-field method with both the LKB and EUD models with Emami and Rancati's parameters was $40 \%$ and $16 \%$ lower than the three-field method, respectively, while for the spinal cord, the results were in contrast to the larynx; in the four-field method, the NTCP value of the spinal cord was greater than that of the three-field method, it can be said that the reason for increasing spinal cord NTCP in the four field technique is because of the spinal cord is located underneath the posterior supraclavicular field with the $15 \mathrm{MV}$ beam.

Laryngeal edema should be considered as a recognizable morphological change associated with the defect in swallowing and voice [11,32]. Feng et al reported a significant correlation between respiratory problems evaluated with video fluoroscopy and mean laryngeal dose [33]. A similar correlation between mean dose of the supraglottic larynx and dysphagia assessed by questionnaires was reported by Jensen et al [34] and Caglar et al [35] with threshold values of approximately 45-50 Gy. Based on the findings of the articles with EUD <30-35 Gy, the G2-G3 laryngeal edema significantly decreased [24]. In this study clearly the mean dose and EUD of the larynx is reduced in the Shielded method. The findings of this study are related to the dose received and the NTCP of the larynx by Rancati et al [24] and Claus et al [36], with the difference that the IMRT method was also studied in those studies. 
In this study, the dose of spinal cord as another sensitive tissue studied, didn't exceed 46 Gy in order to prevent secondary complications, without reducing the dose of PTV from the maximum value. The findings of the study on spinal cord NTCP are consistent with the findings of Kan et al [37], Boughalia et al [38] and Kam et al [39].

In the previous studies, the larynx NTCP had not been calculated with the EUD model; therefore, the value of "a" for the laryngeal tissue in the EUD model was calculated from the $\mathrm{n}=1 / \mathrm{a}$. The "a" value obtained from the Rancati's parameters was equal to 2.2, compare to 12.5 derived from Emami's parameter (Table 5). The NTCP value from EUD model is more consistent with the LKB model when Rancati's parameters were used for calculation. But the NTCP calculated with the EUD model with Emami's parameter istotally different from the LKB model. There for, the findings from EUD model for larynx require further investigation.

In this study, as shown in Tables 4 and 5, the two LKB and EUD models do not equal in the normal tissue complication probability , according to a study by Moiseenko et al, the observed variation in NTCP results is rooted in the radiobiological models and their parameters [40].

\section{Conclusion}

In this study, between groups of with and without shield, there is a significant difference between NTCP values and mean dose of larynx and little difference in spinal cord tissue. As a result, it can be said that the change in the number of fields doesn't have much effect on the dose of the sensitive tissues of the spinal cord and larynx in the first stage of treatment, but it can't be ignored its effect on the reduction of NTCP in the four field technique

\section{Acknowledgements}

The authors would like to thank Vice Chancellor for research of Tabriz University of Medical Sciences for their financial support (Grant No. 1395-234). Thanks also to Omid research and therapeutic center in providing facilities necessary to this work.

\section{References}

[1] Peszynska-Piorun M, Malicki J, Golusinski W. Doses in organs at risk during head and neck radiotherapy using IMRT and 3D-CRT. Radiol Oncol; 2012;46(4):328-336.

[2] Yeh SA. Radiotherapy for Head and Neck Cancer. Semin Plast Surg. 2010; 24(2):127-136.

[3] Putipun Puataweepong. Advanced Radiation Therapy for Head and Neck Cancer: A New Standard of Practice. Ramathibodi Hospital, Mahidol UniversityThailand.

[4] Bakiu E, Telhaj E, Kozma E, et al. Comparison of 3D CRT and IMRT Tratment Plans. Acta Inform Med. 2013;21(3):211-212.

[5] Molazadeh M, Saberi H, Rahmatnezhadi L, et al. Evaluation the Effect of Photon Beam Energies on Organ at Risk Doses in ThreeDimensional Conformal Radiation Therapy. Res J Appl Sci Eng Technol. 2013;6(12):2110-2117.

[6] Intensity Modulated Radiation Therapy. Irsa.org. Retrieved 2012-04-20.

[7] Herman TF, Schnell E, Young J, et al. Dosimetric comparison between IMRT delivery modes: Step-and-shoot, sliding window, and volumetric modulated arc therapy - for whole pelvis radiation therapy of intermediate-to-high risk prostate adenocarcinoma. J Med Phys. 2013;38(4):165-72.

[8] Herrassi MY, Bentayeb F, Malisan MR. Comparative study of four advanced 3d-conformal radiation therapy treatment planning techniques for head and neck cancer. J Med Phys. 2013;38(2):98-105.

[9] Fung K, Yoo J, Leeper HA, et al. Effects of head and neck radiation therapy on vocal function. J Otolaryngol. 2001;30(3):133-139.

[10] Breen S, Craig T, Bayley A, et al. Spinal cord planning risk volumes for intensity-modulated radiation therapy of head-and-neck cancer. Int J Radiat Oncol Biol Phys. 2006;64(1):321-325.

[11] Schultheiss TE, Kun LE, Ang KK, et al. Radiation response of the central nervous system. Int J Radiat Oncol Biol Phys. 1995;31(5):1093-1112.

[12] Emami B. Tolerance of Normal Tissue to Therapeutic Radiation. Rep Radiother Oncol. 2013;1(1):35-48.

[13] Lukarski D, Krstevska V, Petkovska S. A Treatment Planning Comparison of Two Different 3D Conformal Technique for Irradiation of head and neck cancer patients, Proceedings of the Second Conference on Medical Physics and Biomedical Engineering.

[14] Nguyen NP, Ceizyk M, Vos P, et al. Effectiveness of image-guided radiotherapy for laryngeal sparing in head and neck cancer. Oral Oncol. 2010;46(4):283-286.

[15] Hamdan A, Geara F, Rameh C, et al. Vocal changes following radiotherapy to the head and neck for non-laryngeal tumors. Eur Arch Otorhinolaryngol. 2009;266(9):1435-1439.

[16] Rancati T, Schwarz M, Allen AM. Radiation dose-volume effects in larynx and pharynx. Int J Radiat Oncol Biol Phys. 2010;76(3Suppl):S64-S69.

[17] Paulino AC, Arceci RJ. Nasopharyngeal Cancer Treatment \& Management. https://emedicine.medscape.com/article/988165treatment. 2015. 
[18] Grégoire V, de Neve W, Eisbruch A, et al. Intensity-Modulated Radiation Therapy for Head and Neck Carcinoma. Oncologist. 2007;12(5):555-564.

[19] Sanchez-Neito B, Nahum AE. BIOPLAN: software for the biological evaluation of radiotherapy treatment plans. Med Dosim. 2000;25(2):71-76.

[20] Kallman P, Agren A, Brahme A. Tumor and normal tissue responses to fractionated non-uniform dose delivery. Int J Radiat Biol. 1992; 62(2):249-262.

[21] Burman C, Kutcher GJ, Emami B, et al. Fitting of normal tissue tolerance data to an analytic function. Int J Radiat Oncol Biol Phys. 1991;21(1):123-135.

[22] Emami B, Lyman J, Brown A, et al. Tolerance of normal tissue to therapeutic irradiation. Int J Radiat Oncol Biol Phys. 1991;21(1):109-122.

[23] Jones B, Dale R. Mathematical models of tumor and normal tissue response. Acta Oncol. 1999;38(7):883-893.

[24] Rancati T, Fiorino C, Sanguineti G. NTCP modeling of sub-acute/late laryngeal edema scored by fiberopitic examination. Int J Radiat Oncol Biol Phys. 2009;75(30):915-923.

[25] Niemierko A. Goitein M. Modeling of normal tissue response to radiation: the critical volume model. Int J Radiat Oncol Biol Phys. 1993;25(1):135-145.

[26] Luxton G, Keall PJ King CR. A new formula for normal tissue complication probability (NTCP) as a function of equivalent uniform dose (EUD). Phys Med Biol. 2008;53(1):23-36.

[27] Gay HA, Niemierko A. A free program for calculating EUD-based NTCP and TCP in external beam radiotherapy. Phys Med. 2007;23(3-4):115-125.

[28] Allen LX, Alber M, Deasy JO, et al. The use and QA of biologically related models for treatment planning: short report of the TG166 of the therapy physics committee of the AAPM. Med Phys. 2012;39(3):1386-1409.

[29] Oinam AS, Singh L, Shukla A, et al. Dose volume histogram analysis and comparison of different radiobiological models using inhouse developed software. J Med Phys .2011;36(4):220-229.

[30] Gomez D, Cahlon O, Mechalakos J, et al. An investigation of intensity modulated radiation therapy versus conventional twodimensional and 3D-conformal radiation therapy for early stage larynx cancer. Radiat Oncol. 2010;5:74.

[31] Varadharajan E, Swaminathan S, et al. Biological evaluation of 3D conformal radiotherapy and intensity modulated radiotherapy plans in different clinical situations. JIPMER Journal of cancer. 2014;3(1):35-43.

[32] Eisbruch A, Schwarz M, Rasch C, et al. Dysphagia and aspiration after chemoradiotherapy for head-and-neck cancer: Which anatomic structures are affected and can they be spared by IMRT. Int J Radiat Oncol Biol Phys. 2004;60(5):1425-1439.

[33] Feng FY, Kim HM, Lyden TH, et al. Intensity-modulated radiotherapy of head and neck cancer aiming to reduce dysphagia: Early dose-effect relationships for the swallowing structures .Int J Radiat Oncol Biol Phys. 2007;68(5):1289-1299.

[34] Jensen K, Lambertsen K, Grau C. Late swallowing dysfunction and dysphagia after radiotherapy for pharynx cancer: Frequency, intensity and correlation with dose and volume parameters. Radiother Oncol. 2007;85(1):74-82.

[35] Caglar HB, Allen AM, Othus M, et al. Dose to the larynx predicts for swallowing complications following IMRT and chemotherapy. Int J Radiat Oncol Biol Phys. 2007;69:(Suppl. 1):S53-S54.

[36] Kristensen CA, Kjær-Kristoffersen F, Sapru W, et al. Nasopharyngeal carcinoma Treatment planning with IMRT and 3D conformal radiotherapy. Acta Oncol. 2007;46(2):214-220.

[37] Kan MW, Leung LH, Yu PK. The use of biologically related model (Eclipse) for the intensity-modulated radiation therapy planning of nasopharyngeal carcinoma. PLoS One. 2014;9(11):e112229.

[38] Boughalia A, Marcie S, Fellah M, et al. Assessment and quantification of patient set-up errors in nasopharyngeal cancer patients and their biological and dosimetric impact in terms of generalized equivalent uniform dose (gEUD), tumour control probability (TCP) and normal tissue complication probability (NTCP). Br J Radiol. 2015;88(1050):20140839.

[39] Kam MK, Chau RM, Suen J, et al. Intensity-modulated radiotherapy in nasopharyngeal carcinoma: dosimetric advantage over conventional plans and feasibility of dose escalation. Int J Radiat Oncol Biol Phys. 2003;56(1):145-147.

[40] Moiseenko V, Battista J, Van DJ. Normal tissue complication probabilities (dependence on choice of biological model and dosevolume histogram reduction scheme). Int J Radiat Oncol Biol Phys. 2000;46(4):983-993. 